\title{
Facility for performance tests of security structures to U.S. Department of State standards
}

\author{
R. M. Gutkowski \& C. B. Turnbull-Grimes \\ Department of Civil \& Environmental Engineering, \\ Colorado State University, USA
}

\begin{abstract}
In 2005, a testing ramp was designed and constructed to allow manufacturers to test highway safety barriers at a relatively low cost before a full-scale government regulated test. In order to expand the use of this facility, upgrades were made to meet standards set by the U.S. Department of State for testing terrorism barriers. The main objective was to ensure that the modifications adequately increase the velocity and subsequent impact energy.
\end{abstract}

Keywords: facility, tests, security, structures, vehicle, impact.

\section{Introduction and background}

This paper describes the modification of a vehicle crash test facility, located at the Engineering Research Center of Colorado State University, to be able conduct a test meeting official government standards to endorse terrorism barriers as level K12 effective. As a result of terrorism, the Department of State (DOS) test methods were restructured according to the Department of State Report SD-STD02.01, Revision A, March 2003: Test Method for Vehicle Crash Testing of Perimeter Barriers and Gates (SD STD-02.01) [1]. New test methods, test vehicle regulations and performance policies were required. When completed, the facility will be able to complete the full DOS tests with the exception of the optional payload explosives. 


\section{Overview of NCHRP project}

The original facility enabled a user to impact roadway safety barriers so as to meet most requirements set forth in federal NCHRP Report 350 for a Test Level 3 Impact Severity [2-4].

An existing hill and profile were modified to accommodate the ramp. The ramp was built at a height of $14.0 \mathrm{~m}$ and a $20^{\circ}$ angle of incline. The base was fitted with a curved concrete transition section as shown in Figure 1 and a steel Ibeam guide was placed down the centerline of the ramp.

To meet NCHRP 350 requirements at the velocity possible from the ramp, the test vehicle needed to weigh at least $5600 \mathrm{~kg}$. The impact angle with the barrier was the required 90 degrees. A medium duty truck with a certain bumper height had to be used, thus a salvaged LoadStar was used (see Fig. 2). The base weight

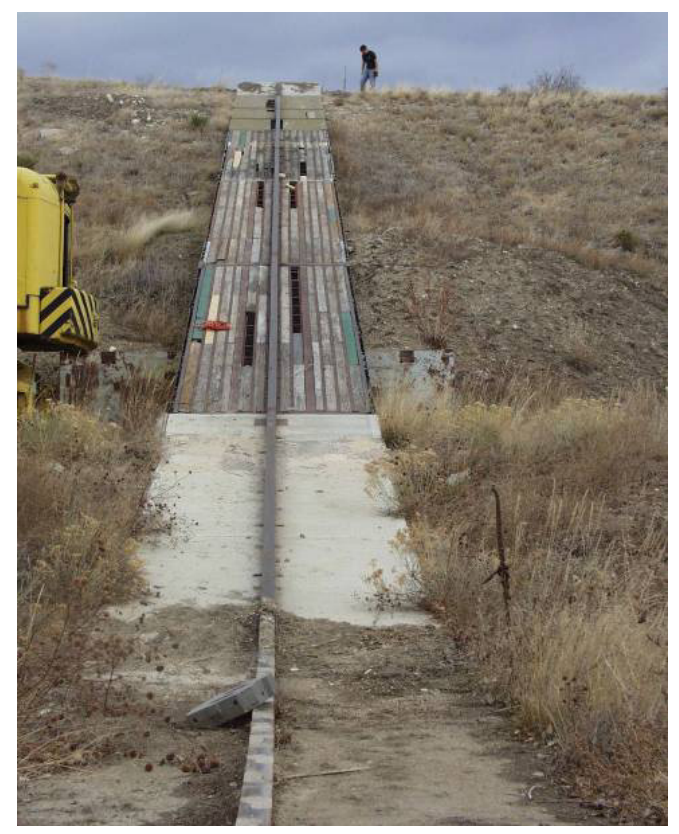

Figure 1: Current view of ramp.

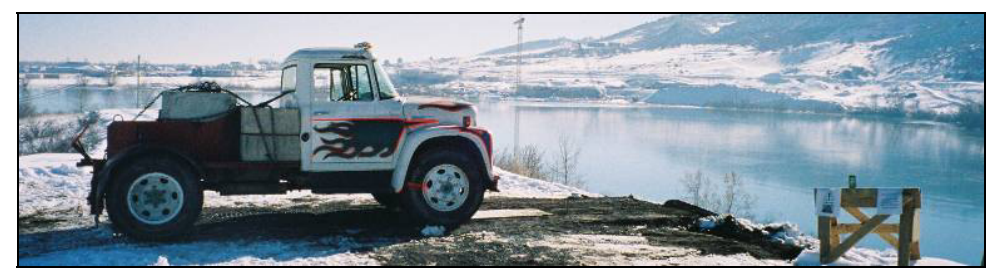

Figure 2: $\quad$ LoadStar 1700 test vehicle. 

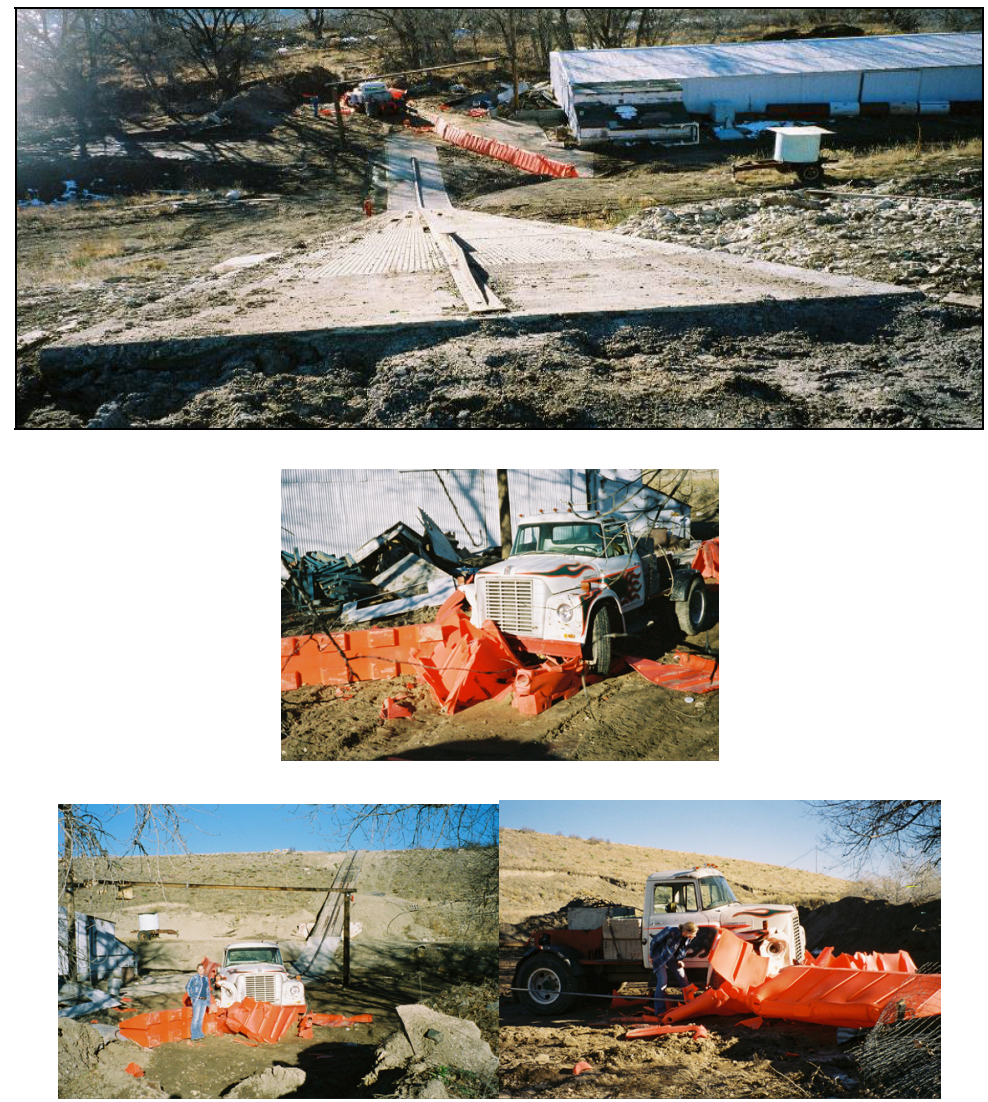

Figure 3: $\quad$ Truck and barriers after impact.

of the truck was $3338 \mathrm{~kg}$ and after addition of concrete blocks was $6414 \mathrm{~kg}$. The truck rolled down the hill while guided by the steel I-beam. Figure 3 shows the outcome of the impact. High speed video camera images indicated the impact velocity was $64.4 \mathrm{~km} / \mathrm{h}, 3.9 \mathrm{~km} / \mathrm{h}$ faster than the base NCHRP Level 3 requirements for this vehicle weight.

\section{DOS phase 1}

\subsection{Department of state report SD-STD-02.01 revision A}

To satisfy SD-STD-02.01 Revision A for a K12 rating the kinetic energy required at head-on impact is $1695 \mathrm{~kJ}$. This can be obtained by modifying the weight and velocity of the truck, but the truck characteristics must remain the same. Medium duty trucks are necessary as light duty trucks cannot provide enough impact energy and heavy duty trucks "are more conspicuous, more difficult to operate, need longer distances to accelerate, and, if capacity, do not 
need to ram given typical setbacks." Newer medium duty trucks and a requirement for firm attachment of any additional load to the truck are included. Other changes include the location of the measurement origins, required setback between the inside edge of the barrier and building being protected), and an allowable penetration of $1.0 \mathrm{~m}$. The soil the barrier is anchored into must meet specific requirements, too.

\subsection{Initial considerations}

The energy requirements for the DOS standard are shown in Table 1.

Table 1: $\quad$ Impact condition designations For a GVW of 6,800 kg (15000 lbs).

\begin{tabular}{|c|c|c|c|}
\hline $\begin{array}{c}\text { Nominal } \\
\text { Impact } \\
\text { Speed }\end{array}$ & $\begin{array}{c}\text { Permissible } \\
\text { Impact Speed } \\
\text { Range }\end{array}$ & Kinetic Energy & Designation \\
\hline $\begin{array}{c}80 \mathrm{kph} \\
(50 \mathrm{mph})\end{array}$ & $\begin{array}{c}75.0 \text {-above } \mathrm{kph} \\
(47.0-56.9 \mathrm{mph})\end{array}$ & $\begin{array}{c}1,695,000 \mathrm{~J} \\
(1,250,000 \mathrm{ft}-\mathrm{lb})\end{array}$ & $\mathrm{K} 12$ \\
\hline $\begin{array}{c}65 \mathrm{kph} \\
(40 \mathrm{mph})\end{array}$ & $\begin{array}{c}60.1-75.0 \mathrm{kph} \\
(38.0-46.9 \mathrm{mph})\end{array}$ & $\begin{array}{c}1,085,000 \mathrm{~J} \\
(800,000 \mathrm{ft}-\mathrm{lb})\end{array}$ & $\mathrm{K} 8$ \\
\hline $\begin{array}{c}50 \mathrm{kph} \\
(30 \mathrm{mph})\end{array}$ & $\begin{array}{c}45.0-60.0 \mathrm{kph} \\
(28.0-37.9 \mathrm{mph})\end{array}$ & $\begin{array}{c}610,000 \mathrm{~J} \\
(450,000 \mathrm{ft}-\mathrm{lb})\end{array}$ & $\mathrm{K} 4$ \\
\hline
\end{tabular}

To meet DOS STD-02.01, a kinetic energy of $1695 \mathrm{~kJ}$ must be reached. Using Eq. (1), the required IS with a mass of $6804 \mathrm{~kg}(15000 \mathrm{lbs})$ and impact angle of $90^{\circ}$, gives a required impact velocity of $80 \mathrm{~km} / \mathrm{h}$.

$$
I S=\frac{1}{2} M(v \sin \theta)^{2}
$$

where $\mathrm{M}=$ mass of vehicle, $\mathrm{v}=$ velocity, and $\theta=$ angle of impact. Equating the potential and kinetic energy equations $\left(\mathrm{mgh}=1 / 2 \mathrm{mv}^{2}\right)$, for the target velocity of 80 $\mathrm{km} / \mathrm{h}$ the required height, $\mathrm{h}$, is $25.5 \mathrm{~m}$, i.e. $11.5 \mathrm{~m}$ above the top of the existing ramp, an impossibility.

A spring to accelerate the vehicle at the outset was considered, but no springs with a needed spring constant and ability to accelerate the vehicles sufficiently in $4.6 \mathrm{~m}$ was found. Climbing ropes can stretch to $120 \%$ of their original length, but the maximum working capacity of most climbing ropes is $9.4 \mathrm{kN}$, much less than the estimated $66.7 \mathrm{kN}$ expected from tightening the rope.

\subsection{Approach taken}

The existing ramp creates a free-fall velocity of only $64.0 \mathrm{~km} / \mathrm{h}$. It was decided to place a trailer at the top of the ramp and pull on the truck to create an initial velocity of $16.0 \mathrm{~km} / \mathrm{h}$ before it contacted the ramp. A side view of the trailer is 


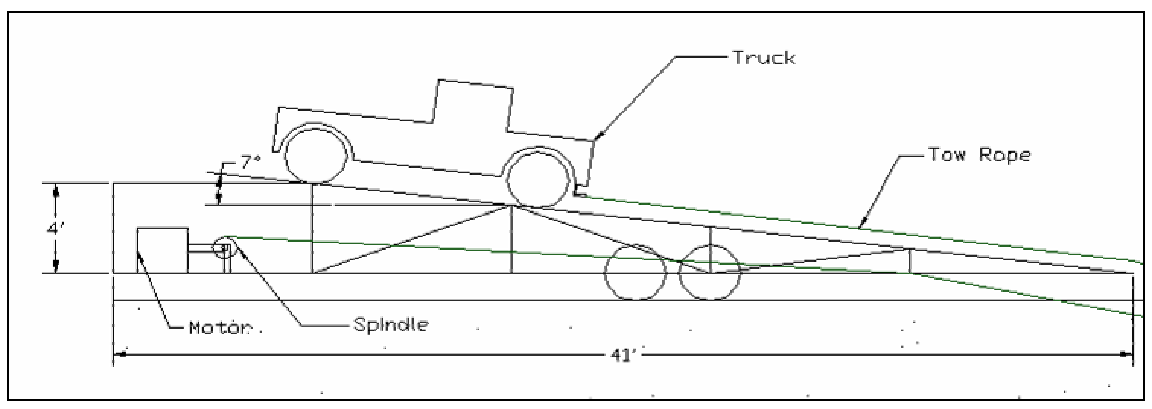

Figure 4: $\quad$ Trailer side view.

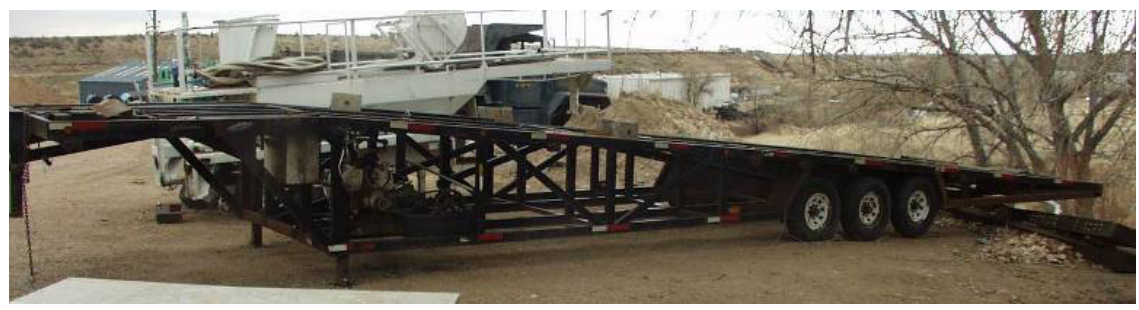

Figure 5: $\quad$ Trailer with modifications.

given in Figure 4. An engine mounted on the trailer acts as a winch to supply the force to accelerate the truck. A tow rope goes from the winch to the ramp, under the ramp down to the bottom of the ramp, then on top of the ramp back to the top, and up to the trailer.

\section{Test configuration}

\subsection{Trailer and modifications made to ramp}

As shown in Figures 5 and 6, the multi-vehicle transport trailer has been modified with a mounted hydro seeder engine placed in the trailer framework. It has a length of $12.54 \mathrm{~m}$ and a height of $1.68 \mathrm{~m}$. It has also been modified to act as a vehicle accelerator

The engine was modified to accommodate a spindle braced at each end, which coils a $113 \mathrm{kN}$ capacity extensible nylon rope around it. The rope passes through the centerline of the trailer, with some modifications made to the cross to allow for smooth passage of the rope.

Figure 7 shows the rope traveling along the ramp. It has free passage underneath the ramp, with the exception of beneath the upper concrete pad. A hole was bored underneath the pad and a steel tube was inserted. At the base of the ramp, a pulley was mounted so that the rope travels along the steel I-beam to the top and finally fastens to the truck. 


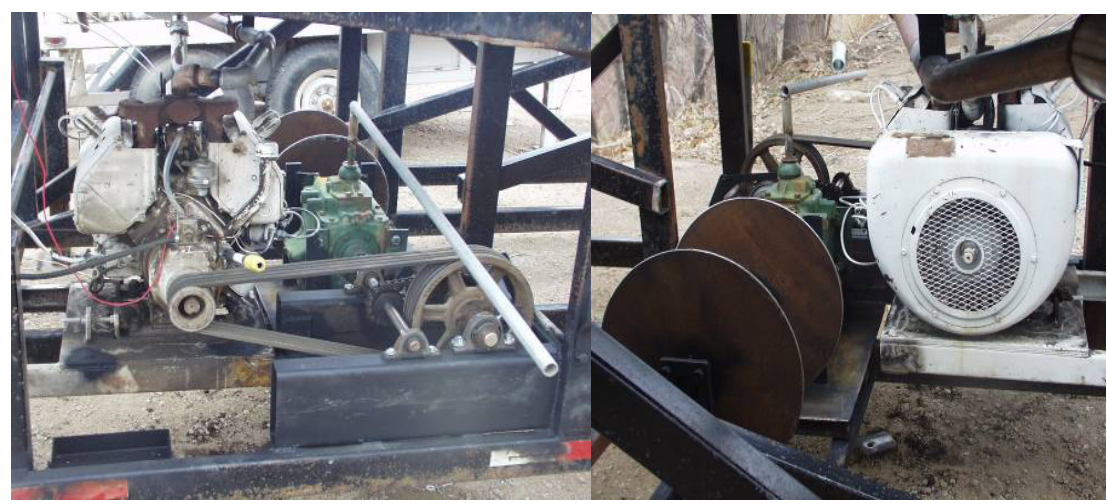

Figure 6: Hydro seeder engine and modifications.

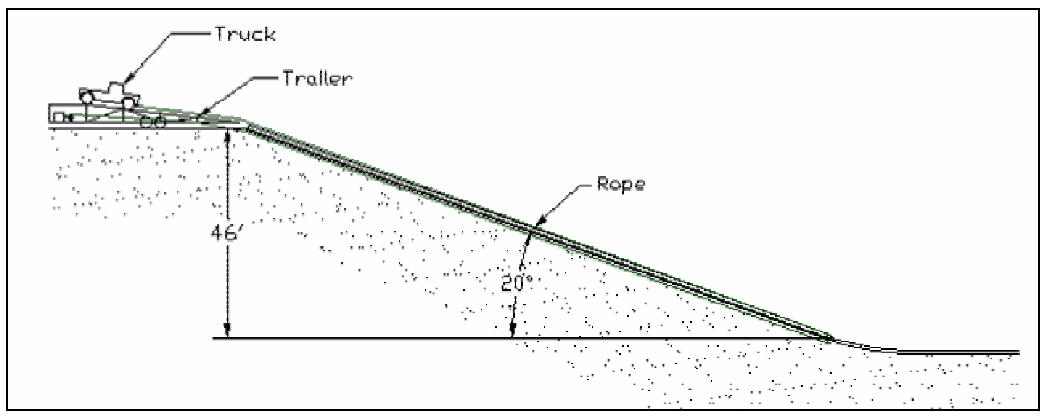

Figure 7: Elevation view of the ramp.

\subsection{Meeting the DOS requirements}

The objective for this project was to increase the existing IS to the DOS need, a $220 \%$ of the original IS. The trailer/rope system provides the additional 16 $\mathrm{km} / \mathrm{h}$. The vehicle weight can be increased to meet the SD STD-02.01 requirements. The LoadStar 1700 medium duty truck used in the NCHRP test had minimal damage and met the requirements of SD STD-02.01, so was used again. To meet the weight requirement of $6804 \mathrm{~kg}$, four available concrete blocks can be added, bringing the weight to $7334 \mathrm{~kg}$. It is highly important to keep the truck in line with the ramp, so that the truck does not veer off to one side or the other. The main point of concern was the interface where the truck exits the trailer and enters the ramp.

\subsection{Test setup}

On February 28, 2008, a pilot test of the ramp performance took place. The trailer was moved into position at the top of the trailer by means of a hydraulic winch (see Fig. 8). The rope was connected to the rear end of the underside of the truck, while the guide was placed in line with the I-beam and attached to the 
truck underneath the front bumper (see Fig. 9). Touch pad timers were properly calibrated for the location and timing of the truck's impact with the target specimen.

Several rows of portable roadway and a large pile of sand and gravel were used to stop the truck.

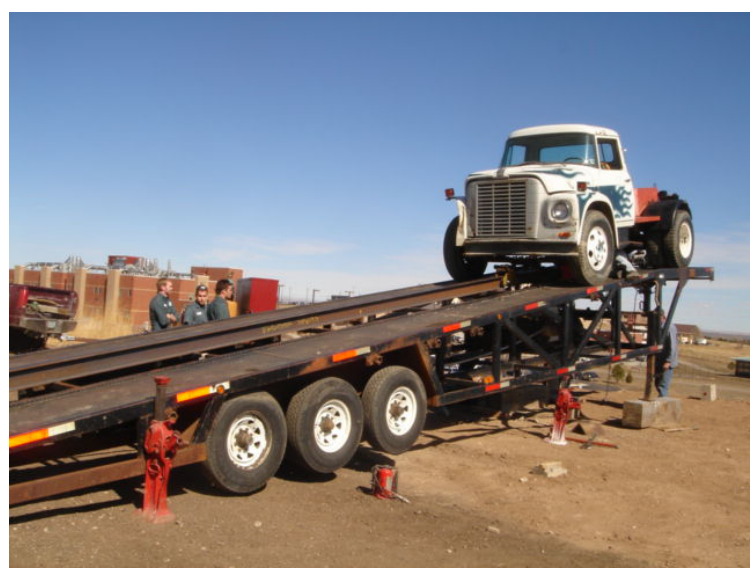

Figure 8: $\quad$ Truck on trailer.

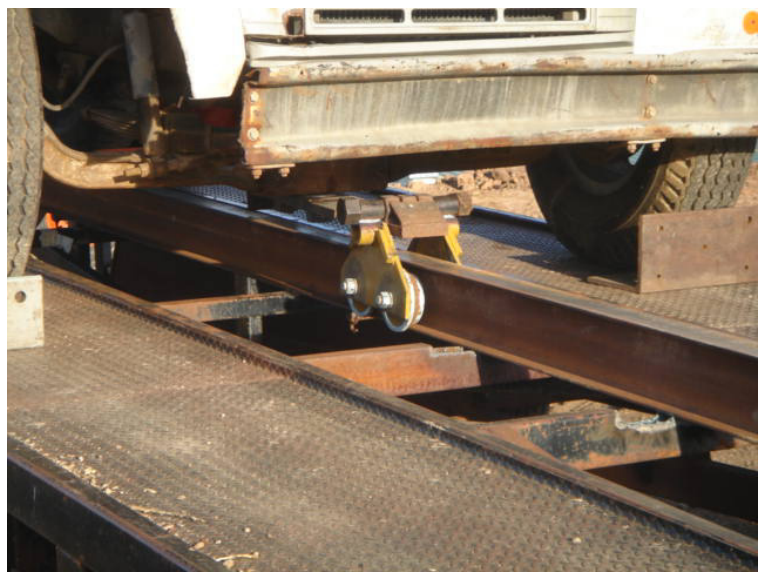

Figure 9: $\quad$ Attached truck guide.

\section{Test run}

Once the setup had been completed, the rope was tightened by the winch and then the brake was released. Two problems occurred at the outset. As the run was set in motion, the motor pulling the rope was geared too high at the time and stalled. The rope slacked too soon, reducing its pull. The bar holding the guide was configured to clear the junction between the trailer and the ramp, but did 
not. It bent and then scraped the I-beam as it traveled the ramp and slowed the truck significantly. The truck remained attached, traveled straight and hit the barriers orthogonally. Timing devices worked and the measured velocity was 54 $\mathrm{km} / \mathrm{h}$, instead of $80 \mathrm{~km} / \mathrm{h}$.

The truck overran the barriers and sat atop the pile of soil (see Fig. 10). The windshield popped out and the truck has been rendered unusable for future tests.

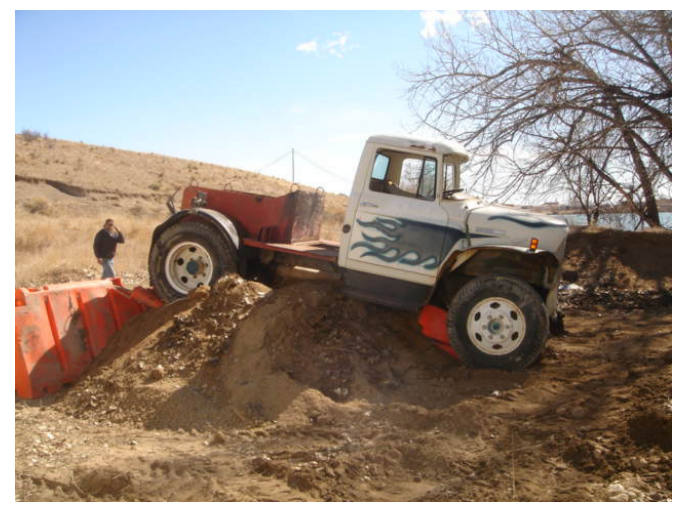

Figure 10: Truck in final position.

\section{Future testing}

Gearing issues must be resolved before future tests. The incline of the ramp will be increased to remove the knuckle at the ramp edge. For a video of the test run and updates, please see: http://www.engr.colostate.edu/StructuresLab.

\section{References}

[1] Certification Standard -Test Method for Vehicle Crash Testing of Perimeter Barriers and Gates, SD-STD-02.01, Revision A, Physical Security Division, Office of Physical Security Programs, Bureau of Diplomatic Security, U.S. Department of State, Washington, D.C., March 2003

[2] Butler, M. L., and Gutkowski, R.M. Impact Performance Testing of Roadway Safety and Security Barriers, MPC Report No. 05-172, North Dakota State University, Fargo, N.D., 2005

[3] Gutkowski, R. M., and M. L. Butler. (2005) Preliminary Impact Tests of Portable Safety/Security Barriers, Proceedings - Safe 2005-First International Conference on Safety and Security Engineering-Rome, Italy, WIT Press, UK.

[4] Transportation Research Board, National Research Council. (1993). National Cooperative Highway Research Program Report 350: Recommended Procedures for the Safety Performance Evaluation of Highway Features. 